Article published in Physica Scripta T128 (2007) 106

\title{
Erosion of tungsten and carbon markers in the outer divertor of ASDEX Upgrade
}

\author{
M Mayer ${ }^{1}$, V Rohde ${ }^{1}$, G Ramos ${ }^{2}$, E Vainonen-Ahlgren ${ }^{3}$, \\ J Likonen ${ }^{3}$, J L Chen ${ }^{1} \ddagger$ and ASDEX Upgrade team \\ ${ }^{1}$ Max-Planck-Institut für Plasmaphysik, EURATOM Association, Boltzmannstr. 2, \\ D-85748 Garching, Germany \\ ${ }^{2}$ CICATA-Qro, Instituto Politécnico Nacional, José Siurob 10, Col. Alameda, 76040 \\ Querétaro, México \\ ${ }^{3}$ Association EURATOM-TEKES, VTT Processes, PO Box 1000, 02044 VTT, \\ Espoo, Finland \\ E-mail: Matej.Mayer@ipp.mpg.de
}

\begin{abstract}
The erosion of tungsten and carbon marker layers was studied in the outer divertor of ASDEX Upgrade. The outer strike point area and a large fraction of the outer baffle are net erosion areas for both materials. The net erosion rate of carbon is about 10-20 times larger than the net erosion rate of tungsten. The erosion is strongly inhomogeneous due to surface roughness, with a large erosion on plasma exposed areas of the rough surfaces, and deposition in recessions and pores.
\end{abstract}

PACS numbers: 52.40.Hf; 52.55.Fa; 82.80.Yc; 82.80.Ms

\section{Introduction}

Major disadvantages of carbon as plasma facing material are its high erosion yield by hydrogen bombardment and its ability to trap large amounts of hydrogen by codeposition. Tungsten shows a much smaller erosion by hydrogen bombardment, and does not co-deposit with hydrogen. It can be, however, eroded by bombardment with heavier plasma impurities such as beryllium, boron or carbon, thus resulting in considerably larger erosion yields than by hydrogen bombardment alone [1].

As was already shown at JET [2] and ASDEX Upgrade [3], the outer divertor is a net erosion area. In order to investigate net and gross carbon and tungsten erosion in $\ddagger$ Permanent address: Institute of Plasma Physics, Chinese Academy of sciences, Hefei 230031, P.R. China 


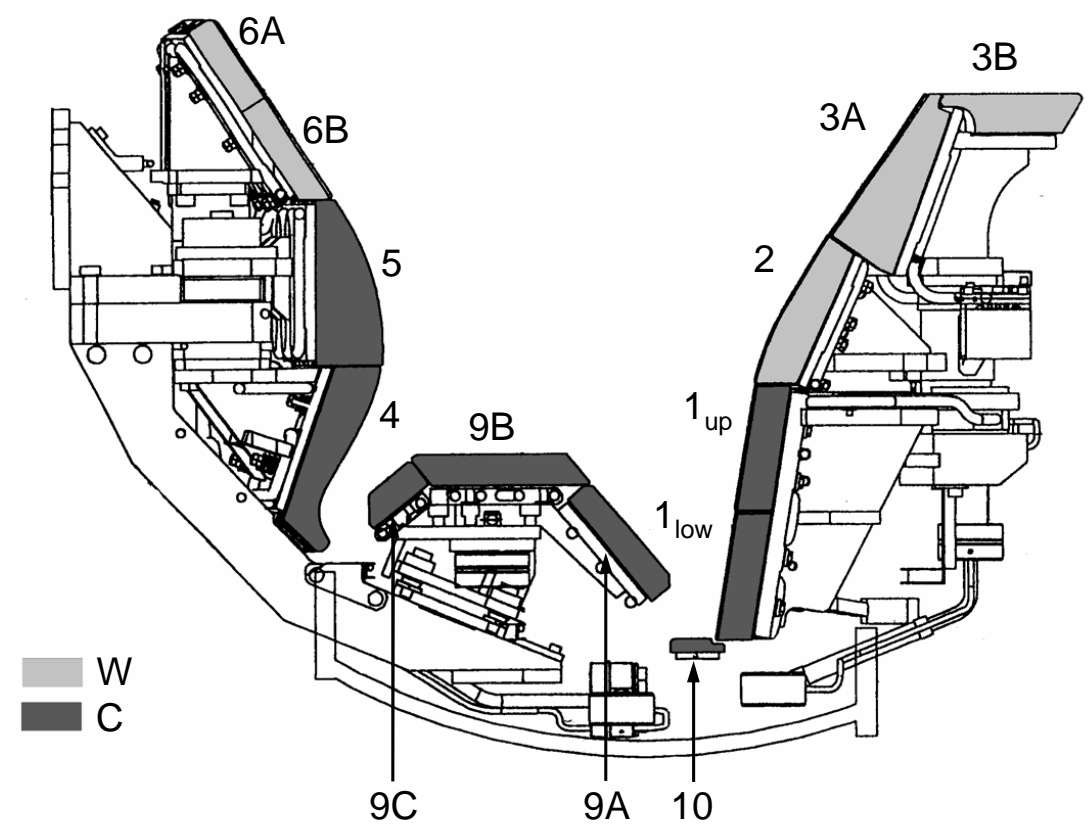

Figure 1. Cross-section of the ASDEX Upgrade divertor IIb during the discharge period 2004-2005. Numbers are tile numbers. Light gray indicates tiles coated with $\mathrm{W}$, dark grey are non-coated carbon tiles.

the ASDEX Upgrade divertor IIb, a poloidal set of carbon divertor tiles was coated with tungsten and carbon marker stripes, thus allowing a direct comparison of the erosion of these two materials under the conditions in the outer ASDEX-Upgrade divertor.

\section{Experimental}

The main chamber of ASDEX Upgrade was almost fully tungsten covered during the 2004-2005 discharge campaign [4]. Only the ICRH and some auxiliary limiters still consisted of carbon.

A cross-section of the ASDEX Upgrade divertor IIb, as used during the discharge campaign 2004-2005, is shown in Figure 1. Tiles 6A, 6B, 5 and 4 form the inner, and tiles 10, 1, 2 and $3 \mathrm{~A}$ the outer divertor. Tiles $9 \mathrm{~A}-9 \mathrm{C}$ are the roof baffle. Most tiles consist of fine grain graphite manufactured by Ringsdorff, except the inner strike point tile 4, which is carbon fibre composite (CFC). Tiles 6A, 6B, 2, 3A, and 3B were coated with 3-4 $\mu \mathrm{m}$ W using physical vapor deposition (PVD), the rest of the tiles were still carbon.

A poloidal section of outer divertor tiles in sector 12 was coated with two marker stripes:

(i) Tungsten marker: $1.6 \times 10^{18} \mathrm{~W}$-atoms $/ \mathrm{cm}^{2}$ (about $260 \mathrm{~nm}$ ) on tiles $2,3 \mathrm{~A}$ and $3 \mathrm{~B}$. The strike point tiles $1_{\text {low }}$ and $1_{\text {up }}$ were coated with a thicker layer of $3.5 \times 10^{18}$ $\mathrm{W}$-atoms $/ \mathrm{cm}^{2}(560 \mathrm{~nm})$.

(ii) Carbon marker: $4 \times 10^{19} \mathrm{C}$-atoms $/ \mathrm{cm}^{2}$ (about $4 \mu \mathrm{m}$ ) on $1 \times 10^{18} \mathrm{Re}$-atoms $/ \mathrm{cm}^{2}$ 
(about $150 \mathrm{~nm}$ ). The Re serves as marker for ion beam analysis and allows to determine the thickness of the overlaying carbon layer from the energy shift of the Re peak.

The marker layers were deposited using a pulsed plasma arc [5], the marker layer width was about $15 \mathrm{~mm}$.

The tiles were analyzed before and after installation with Rutherford-backscattering (RBS) using $1.6 \mathrm{MeV}$ and $2.5 \mathrm{MeV}$ protons at $165^{\circ}$. The spectra were evaluated with the program SIMNRA [6, 7, 8], using non-Rutherford scattering cross-sections from $[9,10,11]$.

The tiles were installed in 11/2004 and removed in 08/2005. 733 useful plasma discharges with a total discharge time of $3057 \mathrm{~s}$ in divertor configuration were performed during this period, and six boronizations were applied for wall conditioning.

The ion fluence to the divertor tiles was measured with Langmuir probes [12].

\section{Results and discussion}

\subsection{Erosion of tungsten}

The distribution of strike point positions during the whole discharge campaign is shown in Figure 2. The strike point was always on the load-bearing tiles $1_{\text {up }}$ and $1_{\text {low }}$. The ion fluence is roughly proportional to the discharge time on tile 1 , but there is also some ion flux onto tile 2 due to the decay of the particle flux from the separatrix, although the strike point was not positioned on this tile.

The tungsten erosion can be characterized by two different numbers:

(i) The net erosion is given by the difference of the amounts of tungsten before and after exposure, i.e.

$$
E_{\text {net }}=N_{\text {before }}-N_{\text {after }},
$$

with $N_{\text {before }}$ the amount of tungsten (in atoms $/ \mathrm{cm}^{2}$ ) before exposure and $N_{\text {after }}$ the amount after exposure. Net erosion is positive, while net deposition (due to tungsten arriving from the main chamber) is negative.

(ii) The gross erosion is the amount of tungsten eroded from a specific location, taking the additional influx from other locations (such as the main chamber) into account. The gross erosion can be determined approximately from

$$
E_{\text {gross }}=N_{\text {before }}+N_{\text {deposited }}-N_{\text {after }},
$$

with $N_{\text {before }}$ and $N_{\text {after }}$ the amounts of tungsten before and after exposure and $N_{\text {deposited }}$ the amount of additionally deposited W. $N_{\text {deposited }}$ can be determined approximately from the deposition of $\mathrm{W}$ on initially clean carbon areas. The gross erosion is always positive.

This definition of the gross erosion includes prompt redeposition [13], i.e. the gross erosion, as defined within this paper, is approximately the amount of initially eroded 


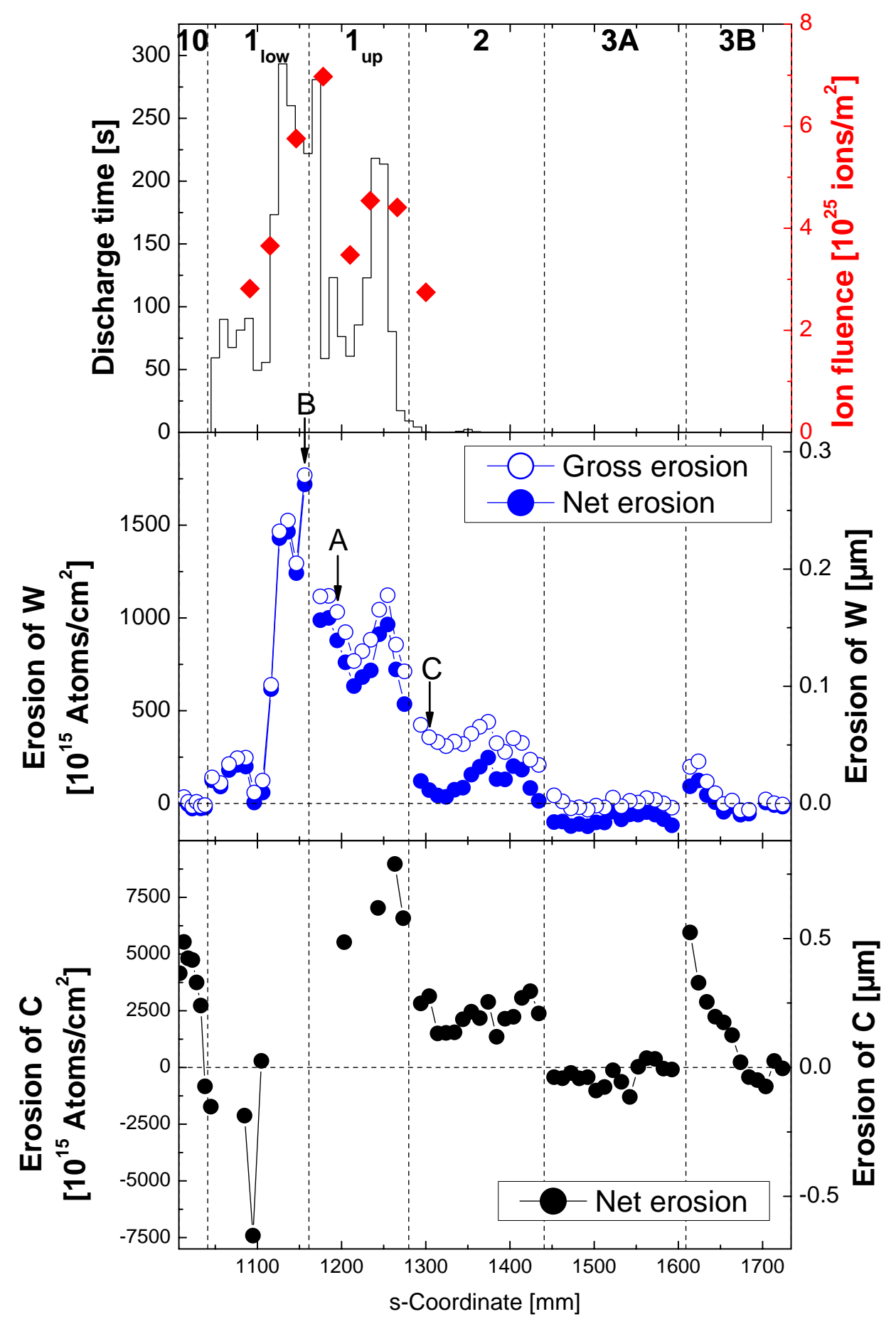

Figure 2. Top: Strike point position during the campaign 2004/2005. Line: Discharge time as obtained from the magnetic reconstruction within $10 \mathrm{~mm}$ (left scale); Symbols: Total ion fluence (right scale). Numbers are tile numbers. Middle: Net and gross erosion of the tungsten marker stripe. Scanning electron micrographs of areas A, B and $\mathrm{C}$ are shown in Figure 3, Figure 4 and Figure 5. The scale at the right hand axis was obtained using the theoretical tungsten density of $19.3 \mathrm{~g} / \mathrm{cm}^{3}$. Bottom: Net erosion of the carbon marker stripe. The scale at the right hand axis was obtained using the theoretical carbon density of $2.26 \mathrm{~g} / \mathrm{cm}^{3}$. 
W-atoms minus the amount of promptly redeposited W-atoms. This gross erosion represents the amount of $\mathrm{W}$-atoms which are subject to long-range transport. This definition differs from the gross erosion typically used in papers based on spectroscopic observations, where the gross erosion is defined as the flux of initially eroded W-atoms without taking prompt redeposition into account.

The net and gross W-erosion for the outer divertor are shown in the middle part of Figure 2. The given numbers are lower boundaries for the total erosion due to total removal of the $\mathrm{W}$ marker layer in some places, see below. The largest erosion is observed on the two strike point tiles 1 . The erosion pattern reflects the distribution of strike point positions. Net and gross erosion are almost similar, because tungsten deposition on the carbon tiles is small. The erosion is zero on tile 10, and small on the lowest $5 \mathrm{~cm}$ of tile $1_{\text {low }}$. Gross tungsten erosion is observed on tile 2, but here the net erosion is small: tungsten eroded from the marker stripe is replaced by tungsten redeposited from the plasma, resulting in only minor changes of the mean amount of tungsten. The gross erosion is zero on tile $3 \mathrm{~A}$, and a small net tungsten deposition is observed. Some erosion is observed on the plasma-nearest corner of tile $3 \mathrm{~B}$, followed by an exponentially decreasing erosion when moving away from the plasma.

The maximum tungsten erosion rate on tile 1 is $>0.06 \mathrm{~nm} / \mathrm{s}$. This is comparable to the observed maximum tungsten erosion rate of $\gg 0.03 \mathrm{~nm} / \mathrm{s}$ on the outer strike point of JET [2]. Both numbers are lower boundaries due to total removal of the W marker layer in some places.

Scanning electron micrographs (SEM) of the tungsten marker stripe after exposure are shown in Figure 3-Figure 5. The images were recorded with secondary electrons (SE), which show predominantly the surface topography, but are also sensitive to the atomic number. Tungsten appears more bright in the images, while carbon is darker. The erosion of the W-layer was inhomogeneous due to the rough surface, which was a result of the machining process of the tiles by milling and the grain size of $3-5 \mu \mathrm{m}$. The layer (initial thickness $560 \mathrm{~nm}$ ) was completely eroded on the plasma exposed side of microscopic ridges (see Figure 3). A very similar behavior was already observed on W-layers on CFC in JET [2]. The tile area with maximum erosion is shown in Figure 4. The W-layer has been fully eroded on all plasma exposed faces, but is still present in recessions and pores.

SEM images of area $\mathrm{C}$ on tile 2 are shown in Figure 5. The initial $\mathrm{W}$ thickness was about $260 \mathrm{~nm}$ on this tile. Very similar to the strike point tiles 1 , the tungsten was completely eroded on the plasma exposed faces of the rough surface, but is still present in recessions and pores. However, despite the large gross erosion the net erosion is almost zero, see Figure 2(middle), i.e. the amounts of tungsten before and after exposure are almost identical. This is due to redeposition of tungsten in recessions and pores, which can be observed on the initially clean carbon surface, see Figure 5 (bottom). The same redeposition has to be assumed on the tungsten marker stripe, which explains why the total amount of $\mathrm{W}$ remains almost identical despite the visible erosion. The redeposited tungsten originates either from tungsten coatings in the main chamber, or from the 


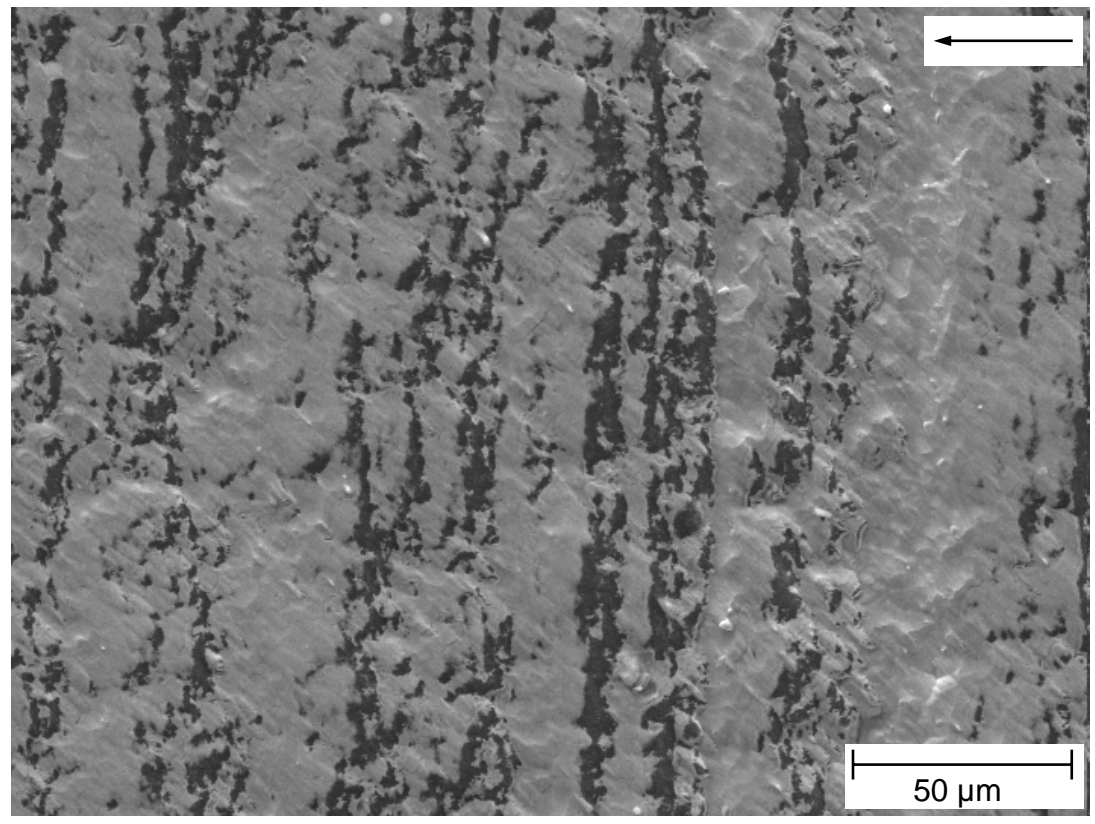

Figure 3. Scanning electron micrograph of area A, see Figure 2. The arrow in the upper right corner indicates the direction of the incident particle flux.

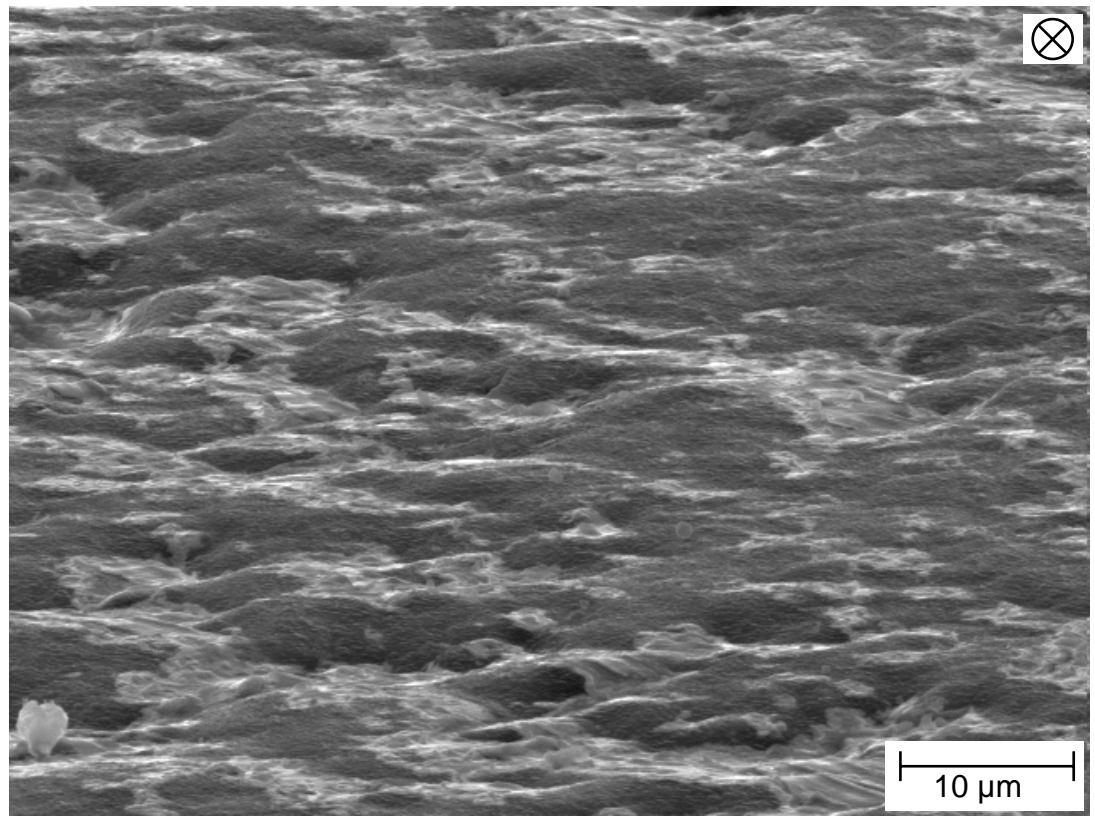

Figure 4. Scanning electron micrograph of area B, see Figure 2. The sample was tilted by $75^{\circ}$. The incident particle flux was directed into the paper plane. 

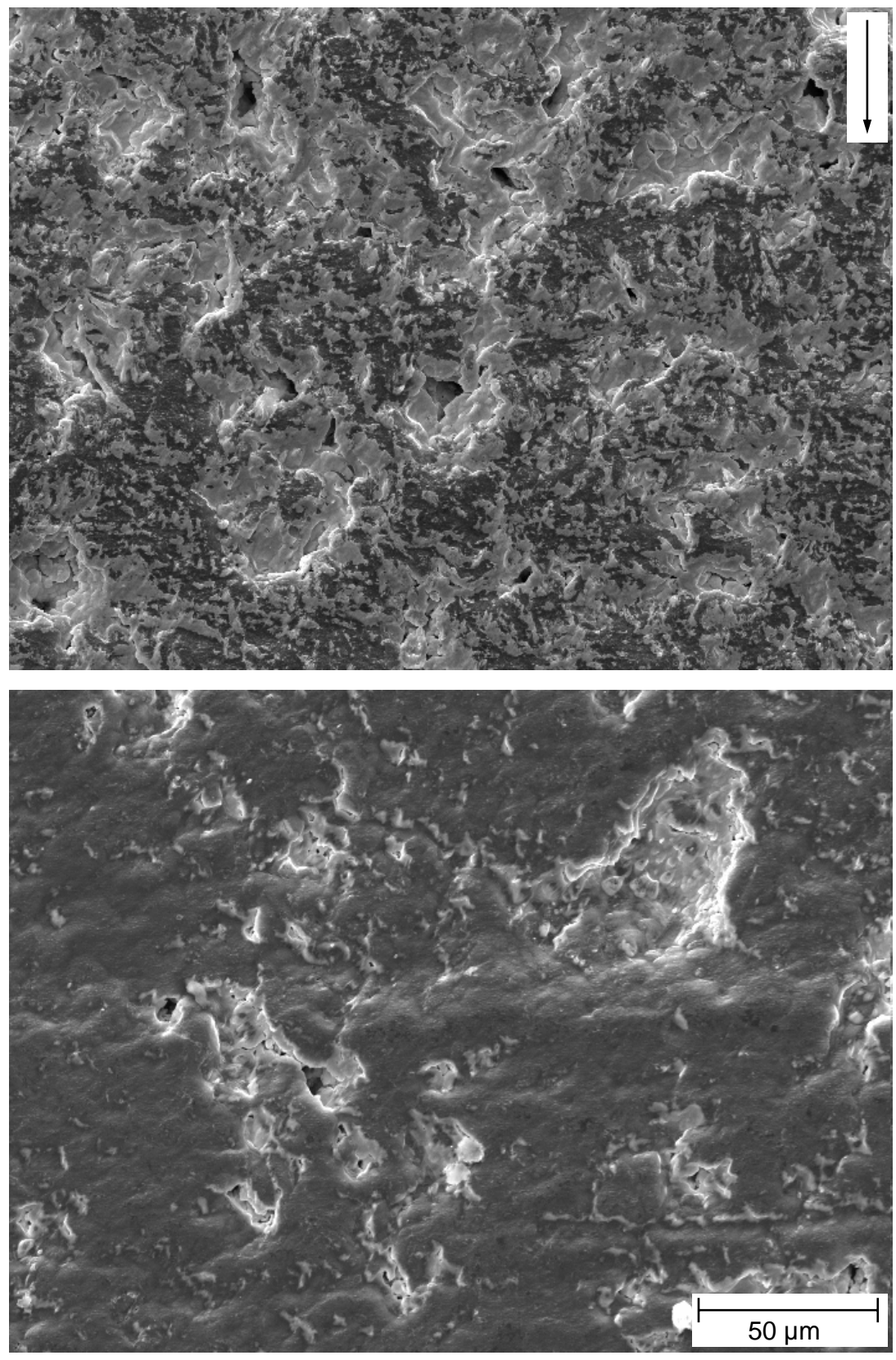

Figure 5. Scanning electron micrograph of area C, see Figure 2. Top: Tungsten marker layer. Bottom: Carbon tile. The arrow in the upper right corner indicates the direction of the incident particle flux.

neighboring tungsten coated divertor tiles.

A strongly inhomogeneous erosion with large erosion on plasma inclined faces of the rough surface and smaller erosion or even deposition in recessions and pores was already observed on rough surfaces in ASDEX Upgrade, TEXTOR and JET [14, 15, 2]. Inhomogeneous erosion therefore seems to be a general phenomenon on rough surfaces, which has to be taken into account in the estimation of coating thicknesses and lifetime considerations. 


\subsection{Erosion of carbon}

The net erosion of the carbon marker is shown in Figure 2(bottom). The marker layer disappeared completely (including the Re interlayer) at several areas of tiles 1, especially at the mostly used strike point area between $s=1100-1200 \mathrm{~mm}$. This was probably not due to erosion, but due to delamination of the marker layer, and these points have not been included in Figure 2(bottom).

The shape of the carbon erosion pattern is very similar to the tungsten erosion distribution, but the net carbon erosion is about 10-20 times larger than the net tungsten erosion. There is also a substantial carbon erosion on tile 10, where the tungsten erosion

is zero: This indicates the presence of low-energetic particles below the sputtering threshold for tungsten, which are still able to erode carbon due to chemical erosion. Net carbon deposition is observed on the lower part of tile $1_{\text {low }}$ and the corner between tile $1_{\text {low }}$ and tile $10(1035<s<1100 \mathrm{~mm})$.

Due to the delamination of the carbon marker layer at some places the total carbon erosion in the outer divertor cannot be obtained from the carbon marker measurements. However, the total carbon erosion from tiles 1 can be obtained from the tungsten erosion pattern using the known carbon to tungsten erosion ratio. The erosion from tiles 1 was about $2.6 \mathrm{~g}$ carbon. In addition $0.2 \mathrm{~g}$ carbon were eroded from tile 10 , resulting in a total carbon erosion of about $2.8 \mathrm{~g}$. It has been already shown in [3], that the erosion of carbon from the roof baffle is small. Kallenbach et al. [16] determined the carbon influx from the outer divertor to be about $1 \mathrm{~g}$ in the $3000 \mathrm{~s}$ of the 2004-2005 campaign. Keeping the large uncertainties (a factor of at least two for both measurements) in mind, this is a reasonable agreement.

The results for the carbon erosion are in qualitative agreement with results obtained during the discharge campaign 2002-2003 [3]: the outer baffle tiles 2 and 3 showed net erosion in 2002-2003, and the marker layer on tiles 1 has completely disappeared. After additional experiences with carbon marker layers in the upper divertor in 2003-2004 and the current results from 2004-2005 it has to be concluded, that a total disappearance of these marker layers is an indication of delamination. Nevertheless, the conclusion in [3], that the outer divertor is a net erosion area, is confirmed by the current measurements. Extrapolating the current results to the 2002-2003 campaign gives a maximum carbon erosion of about $3 \mu \mathrm{m}$, instead of about $7.5 \mu \mathrm{m}$.

The erosion of $\mathrm{W}$ is dominated by sputtering by boron and carbon impurities. The erosion yield at plasma temperatures of $10-30 \mathrm{eV}$ and a carbon impurity concentration of $1 \%$ is about $10^{-5}-10^{-3}$ [1]. The actual erosion is smaller due to prompt redeposition [13]. The gross erosion yield from our measurements is about $1-3 \times 10^{-4}$, which is within the range of possible values. Due to the strong plasma temperature dependence of the erosion yield, the long term erosion is dominated by (even few) discharges with hot divertor plasmas, while discharges with low plasma temperatures have only a small contribution to the total erosion.

The erosion yield of carbon by deuterium is about $10^{-2}[17]$ and depends on incident 
flux [18, 19]. Without prompt redeposition, the ratio of carbon to tungsten erosion therefore should be in the range 10-1000. With prompt redeposition this ratio should increase, while additional deposition of carbon from the main chamber would decrease this ratio. Keeping this large uncertainties in mind, our result for the ratio of net carbon to net tungsten erosion of $10-20$ is within the large range of possible values.

\section{Conclusions}

The erosion of tungsten and carbon marker layers was studied in the outer divertor of ASDEX Upgrade. The strike point area and a large fraction of the outer baffle are net erosion areas for both materials. The erosion of carbon is about 10-20 times larger than the erosion of tungsten. The erosion is strongly inhomogeneous due to surface roughness, with a large erosion on plasma exposed areas of the rough surfaces, and deposition in recessions, and pores. These microscopic areas with different erosion and deposition characteristics are only micrometer apart. This will eventually result in a smoothing of the initial rough surface. This effect is difficult to observe in today's machines due to the limited discharge time, but may play an important role in future long-pulse or steady-state machines like ITER or W7-X.

\section{Acknowledgments}

Ion beam analysis measurements by B. Tyburska and H. Kulinski and the technical assistance by J. Dorner and M. Fußeder are gratefully acknowledged. E. VainonenAhlgren and J. Likonen are thankful to the Association EURATOM-Tekes for the financial support.

\section{References}

[1] K. Krieger, H. Maier, R. Neu, and ASDEX Upgrade Team. J. Nucl. Mater. 266-269 (1999) 207.

[2] M. Mayer, J. Likonen, J.P. Coad, H. Maier, M. Balden, S. Lindig, E. Vainonen-Ahlgren, V. Philipps, and JET-EFDA Contributors. J. Nucl. Mater.. In print.

[3] M. Mayer, V. Rohde, J. Likonen, E. Vainonen-Ahlgren, K. Krieger, X. Gong, J. Chen, and ASDEX Upgrade Team. J. Nucl. Mater. 337-339 (2005) 119.

[4] R. Neu, V. Bobkov, R. Dux, A. Kallenbach, Th. Pütterich, H. Greuner, O. Gruber, A. Herrmann, Ch. Hopf, K. Krieger, C.F. Maggi, H. Maier, M. Mayer, K. Schmid, W. Suttrop, V. Rohde, and ASDEX Upgrade team. J. Nucl. Mater.. In print.

[5] S. Lehto, J. Likonen, J.P. Coad, T. Ahlgren, D.E. Hole, M. Mayer, H. Maier, P. Andrew, and J. Kolehmainen. Fusion Eng. Des. 66-68 (2003) 241.

[6] M. Mayer. SIMNRA user's guide. Tech. Rep. IPP 9/113, Max-Planck-Institut für Plasmaphysik, Garching, 1997.

[7] M. Mayer. SIMNRA, a simulation program for the analysis of NRA, RBS and ERDA. In Proceedings of the 15th International Conference on the Application of Accelerators in Research and Industry (Woodbury, New York, 1999), J. L. Duggan and I. Morgan, Eds., vol. 475 of AIP Conference Proceedings, American Institute of Physics, p. 541.

[8] M. Mayer. Nucl. Instr. Meth. B 194 (2002) 177.

[9] M. Chiari, L. Giuntini, P.A. Mandò, and N. Taccetti. Nucl. Instr. Meth. B 184 (2001) 259. 
[10] A.F. Gurbich. Nucl. Instr. Meth. B 136-138 (1998) 60.

[11] A.F. Gurbich. Nucl. Instr. Meth. B 129 (1997) 311.

[12] M. Weinlich and A. Carlson. Phys. Plasmas 4 (1997) 2151.

[13] D. Naujoks, J. Roth, K. Krieger, G. Lieder, and M. Laux. J. Nucl. Mater. 210 (1994) 43.

[14] D. Hildebrandt, H. Grote, W. Schneider, P. Wienhold, and J. von Seggern. Physica Scripta T81 (1999) 25.

[15] P. Wienhold, F. Weschenfelder, P. Karduck, K. Ohya, S. Richter, and J. von Seggern. J. Nucl. Mater. 266-269 (1999) 986.

[16] A. Kallenbach, R. Dux, J. Harhausen, C.F. Maggi, R. Neu, T. Pütterich, V. Rohde, K.Schmid, E. Wolfrum, and the ASDEX Upgrade Team. J. Nucl. Mater.. In print.

[17] W. Eckstein, C. García-Rosales, J. Roth, and W. Ottenberger. Sputtering data. Tech. Rep. IPP 9/82, Max-Planck-Institut für Plasmaphysik, Garching, 1993.

[18] J. Roth. J. Nucl. Mater. 266-269 (1999) 51.

[19] J. Roth, A. Kirschner, W. Bohmeyer, S. Brezinsek, A. Cambe, E. Casarotto, R. Doerner, E. Gauthier, G. Federici, S. Higashijima, J. Hogan, A. Kallenbach, H. Kubo, J.M. Layet, T. Nakano, V. Philipps, A. Pospieszczyk, R. Preuss, R. Pugno, R. Ruggiéri, B. Schweer, G. Sergienko, and M. Stamp. J. Nucl. Mater. 337-339 (2005) 970. 